
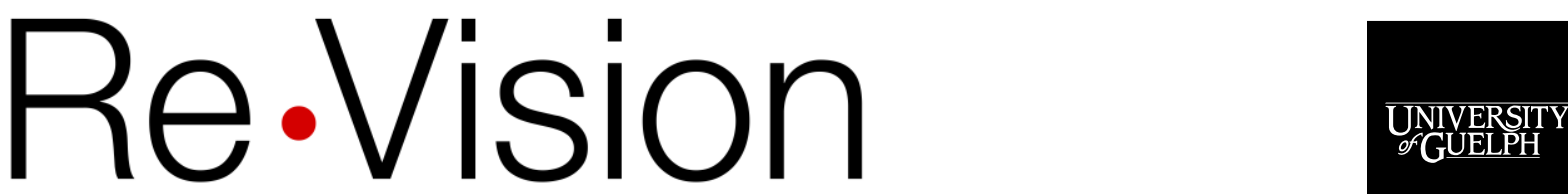

The Centre for Art and Social Justice

\title{
Living dis/artfully with and in illness
}

Patty Douglas

Brandon University

Carla Rice

University of Guelph

Areej Siddiqui

University of Guelph

This is a post-peer-review, pre-copyedit version of an article published in the Journal of Medical Humanities. The final authenticated version is available online at: https://doi.org/10.1007/s10912-019-09606-5.

Recommended citation:

Douglas, P., Rice, C., \& Siddiqui, A. (2020). Living dis/artfully with and in illness. Journal of Medical Humanities. https://doi.org/10.1007/s10912-019-09606-5 


\title{
Living Dis/Artfully with and in Illness
}

\author{
Patty Douglas, Carla Rice, and Areej Siddiqui
}

\section{Abstract}

This article experiments with multimedia storytelling to re-vision difference outside biomedical and humanistic frames by generating new understandings of living dis/artfully with illness. We present and analyze seven short videos created by women and trans people living with illness as part of an arts-based research project that aimed to speak back to hegemonic concepts of disability that create barriers to healthcare. We call for a welcoming in of disability studies' disruptive and re-imaginative orientations to bodily difference to unsettle medicine's humanistic accounts. In turn, we advance medical post-humanistic approaches that call on disability studies to re-embody its theories and approaches.

\section{Keywords}

multimedia storytelling; medical (post) humanities; feminist disability studies; body becoming theory; illness narratives

The stories presented in our paper can be viewed online. 1

1 Go to https://revisioncentre.ca/living-dis-artfully. Type in the password "artfully" to access the album "Living Dis/Artfully with and in Illness". Please note: the videos are intended for readers only and are not for public screening. 


\section{Introduction}

In October 2016, The Hospital for Sick Children in Toronto, Canada launched a fundraising campaign entitled "VS" (versus). Against the driving soundscape of rap artist Donnie Daydream's Undeniable, the dizzying two-minute-long ad juxtaposes blue-black images of battle-ready doctors (surgeons suiting up) and resolute ill children (shaving their heads, strapping on prosthetics, oozing blood) in highly technologized hospital settings alongside combative images of hyper-masculinized, often-racialized adults and children engaged in boxing, wrestling, and other aggressive acts while dressed as knights, superheroes, and soldiers. Over-sized text flashes on the screen: "SICK ISN'T WEAK." "SICK FIGHTS BACK." The enemy is a host of diseases and their effects: kidney failure, cystic fibrosis, autism, cancer, worry, time, defeat. The campaign ends in 'victory'-smashed medical technologies, an exploding clock, a child's bursting arm cast and soldier-like patients and healthcare providers charging into battle (and into technologized medical therapies), including an apocalyptic-like image of a young person in a hospital gown atop a massive pile of mangled wheelchairs, crutches and IV poles.

This fundraising campaign (that is ongoing with another ad recently released) stirred controversy in news media and academic circles. "New SickKids campaign puts 'fierce' new face on what it means to be sick" (Lee-Shanok 2016) declares a CBC headline; "SickKids campaign forgets that kids aren't always warriors" (Picard 2016) counters the Globe \& Mail. On the bioethics forum Impact Ethics, disability scholars Anne McGuire and Michael Orsini (2016) argue, "The campaign message is very clear: there is no room for weakness in the face of illness or disability." They remind us many sick children will never "win the battle" and some diseases listed by the ad, such as 
autism, are not diseases at all, nor are they experienced as such by many people. Within wealthy anglo-western nations, rates of chronic illness are escalating (Frank 2013); yet the logics of the campaign cast the failure to overcome or eradicate illness and disability as a failure of individual strength and will (McGuire and Orsini 2016). The solution offered to the unwanted spectre of living with illness and disability is war, driven by bio-medical technology, medical heroism and a logic of elimination or overcoming.

We begin this way not to weigh in on the SickKids campaign per se. We recognize that restitution and relief from pain are often desired by those living with illness. The issue for us is less restitution itself than its representation: how an enduring, preeminent narrative has come to frame illness in pathologizing and reductive terms; and how this framing marginalizes the experiences and knowledge of those who live with illness and who do not recover. This underscores the larger point of our paper: decades of ground-breaking activism (AIDS, cancer), scholarly work in medical humanities and disability studies, and proliferating first-person narratives (re)valuing non-normative embodiments (Couser 1997) have failed to dislodge the ubiquity of negative ontologies of difference, illness and restitution narratives (Frank 2013). If anything, the SickKids campaign extends mainstream biomedical logics of care and cure further, into childhood—a biomedical overcoming and fixing imperative "seeped into every corner of white Western thought and culture" (Clare 2017, 14) that presses for cure at any cost coupled with an austerity imperative that monetizes and rations care-work and ascribes it as having little economic value. Within such logics, living well with illness and disability becomes unimaginable, even "perverse" or inhumane 
(Patsavas 2014, 208). III, disabled and pained bodies are, in disability scholar Fiona Kumari Campbell's (2005) words, "presumed to be ontologically intolerable" (109).

In this paper, we call for a new kind of attention to illness, one that challenges negative ontologies of difference and embraces illness, disability and pain as a fundamental part of human experience. In contrast to biomedical and humanistic frames that drive conventional approaches to illness like the SickKids campaign, we recuperate the fleshy and artful knowledge of ill people themselves through experiments in multimedia storytelling that offer a more life affirming ontology of difference. We fashion a feminist disability studies approach using ideas from phenomenology and body becoming/new materialist theories—which work in synergistic tension with one another-to disrupt negative ontologies of non-normative embodiment and open possibilities for living well with illness. We build our approach from close descriptions of seven multimedia stories (which we present here) created by women and trans people living with illness as part of Re•Vision: The Centre for Art and Social Justice at the University of Guelph in Ontario, Canada, a research-creation centre founded by Carla Rice that investigates the power of the arts, and especially story, to challenge (mis)representations of difference in and beyond health care (Rice and Mündel 2018). Emerging feminist disability studies theorizing on illness/disability has challenged disability studies and medical humanities approaches_-which have tended to theorize difference through the lens of social oppression (Oliver 1996) and/or lived experience (Frank 2013)—to engage with the materiality of ill/disabled bodies (Garland-Thomson 2011; Rice 2014). We contribute to that scholarship by exploring what it means to live well—even artfully—with illness while not eclipsing impairment, pain and suffering. 
Negative ontologies of non-normative embodiment, we argue, are haunted by the humanist standard of the normative human and driven by cultural anxieties (Sontag 1978) about illness and death, and concomitant biomedical logics of elimination and overcoming. To unsettle humanistic accounts, we analyze videos on illness experiences created as part of a $\mathrm{Re} \bullet V$ ision Centre research project that call for engagement with disability studies' disruptive and re-imaginative orientations to difference. In turn, through our analysis of these films, we engage with medical post-humanistic approaches, which seek to rethink the notion of the human that lies at the centre of humanist thought. We assert that medical posthumanism issues a critically important call to disability studies: to re-embody its theories, which have tended (albeit for strategic political reasons) to evacuate lived experiences of impairment, pain and illness as matters left for medicine.

We foreground narratives of those who live with illness, who reclaim illness as a fundamentally human—creative, relational, sometimes pain-filled and unwanted, even sensuous and artful—form of embodied experience. We experiment with the transformative potential of multimedia storytelling for revisioning illness by opening up space to generate artful representations of living with illness that incorporate the bodily knowledge and vitality of ill people themselves. We use multi-media storytelling methods to expand the kind and quality of available stories about difference (broadly defined) that exist, created through workshop processes that draw on and contribute to accessibility practices from the field of disability arts, which seeks to make art accessible and aligns with the disability rights and justice movements (Chandler, Changfoot, Rice, LaMarre, and Mykitiuk 2018; Rice and Mündel 2019; Rice, LaMarre, 
and Mykitiuk 2018). Multimedia videos created by community members, researchers, care providers, artists and activists through our disability-artist led workshops are short films that pair images, video clips, ambient sound, visual art, voice, music, movement and more to represent complex sensorial experiences that often elude written language or linear narrative structure (Rice, Chandler, Liddiard, Rinaldi and Harrison 2018). We argue that the storytelling method, since it opens space for intra-relationality through multiple sensing channels, is fertile ground through which to experiment with disrupting the normative human standard. By intra-relational we mean the insight forwarded by body becoming and phenomenological theorists that "bodies are formed within a relation rather than formed 'across' or 'between' already-formed bodies” (Fritsch 2015, 52).

To provide some background, the multimedia stories we focus on here were created as part of Mobilizing New Meanings of Disability and Difference, an arts-based research project (PI Rice) that invited disabled people and healthcare providers to engage in multimedia story-making around the theme of changing conceptions of disability in healthcare (Mitchell, Rice, and Pileggi 2018; Rice, Chandler and Changfoot 2016; Rice, Chandler, Harrison, Ferrari, and Liddiard 2015; Rice, Chandler, Rinaldi, Liddiard, Changfoot, Mykitiuk, and Mündel 2017). Drawing on both digital storytelling and participatory filmmaking methods developed over the last few decades in the United States and Britain, we combined and adapted these methods for research, accessibility and creativity purposes, landing on the terminology "multimedia story-making" to encapsulate this processual method (Rice and Mündel 2018). We choose "multimedia" because it encompasses the diverse media forms with which we experiment, and "story- 
making" because it emphasizes how we craft accounts from the flow of raw experiences, and hence the constructivist quality of knowledge claims. From 2012 to 2015, we ran 10 multimedia videomaking workshops in three regions of Ontario: four workshops with adults with disabilities, four with healthcare providers (disabled and nondisabled), and two training workshops with our multidisciplinary research team (which included disabled, nondisabled, and provider researchers) (Viscardis, Rice, Pileggi, Underhill, Changfoot, and Chandler 2018; Montgomery, Mossey, Rice, McCauley, Chandler, Changfoot, and Underhill 2019). Storytellers who were members of our research team participated in analysis; in addition, research team members worked closely with all tellers during these workshop processes and registered/recorded their intentions for their video work to thicken subsequent analyses. Prior to and during the workshops, we made clear verbally and in writing that storytellers owned their stories. Written consent forms also allowed participants to provide different levels of consent regarding the sharing of their stories, including whether or not their story could be screened publicly, presented/ analyzed in an academic publication, used for research purposes only, and/or not used at all. We sought and received approval for the workshops and research process through the University of Guelph's Research Ethics Board (REB\# 12AP010).

We begin by unsettling the myth of the normative human underlying negative ontologies of difference. We describe our approach to illness that draws on the phenomenology and materiality of illness and pain, picking up on and advancing new directions in medical posthumanities and in feminist disability studies, especially new materialist and body becoming perspectives. Feminist new materialist and body 
becoming theories overlap in how "they offer new theories of ontology—of how things come to be things-yet can be distinguished in how they emerge from distinct branches of feminist philosophy" and in how becoming theories apply new materialist insights to bodies in particular (Rice 2018, 538). Central to our approach, we innovate the concept of "living dis/artfully," which we use to graft our video-makers' artful rendering of their lived experiences together with a non-determinist approach to bodily materiality. We present and analyze seven multi-media stories from our project archive that re-imagine illness outside the normative human standard of healthy, pain-free bodies/minds. These we organize along three themes: relationality and rupture; the stubbornness of ill bodies; and the rewriting of bodily scripts. The term "illness" is used interchangeably with "disability" to acknowledge the difficulty, analytically and experientially, of disentangling points of overlap and disjunction between these words, and to break apart binaries of mind/body and nature/culture that underpin them.

\section{Unsettling IIIness Stories: Living Dis/Artfully with Illness}

Feminist philosopher Rosi Braidotti (2013), a leading voice in critical posthumanist thought, has done ground-breaking work in unearthing the western myth of the universal bodymind-the white, male, non-disabled, pain-free, productive human who exists outside time, relationships, culture and contingency, that normative homo sapiens (literally translated 'wise man') at the centre of classic humanist thought. As scholars in disability studies have shown, this humanist ideal haunts disability and illness narratives (Douglas 2013; Erevelles 2011; Douglas, Rice, Runswick-Cole, Easton, Gibson, Gruson-Wood, Klar, and Shields 2019). Grounded in Enlightenment 
philosophies of human perfectibility, scientific hierarchies of gender, race, and disability, and survival-of-the-fittest logics of contemporary neoliberal capitalism, this enduring myth calibrates bodies and minds according to what is considered normative, natural, and optimal. Further, it underpins conventional biomedical approaches of elimination and overcoming—figuring bodies/minds that fall out of its narrow bounds as not quite, lesser than, or disqualified from the fully human.

Despite this critique, theorizing about illness within disability studies and the medical humanities has tended to leave the matter of ill, sick and pained bodies for biomedicine. In so doing, these fields have evacuated the fleshy materiality of bodies from theory, retaining a certain standard of the 'healthy' bodymind as the original, normative or most desirable state (Garland-Thomson 2011). This is due, in part, to the influence of the social model of disability, which makes a clear distinction between impairment and disability (like early feminist distinctions between sex and gender) to foreground disability as a social and not an individual problem of impaired bodyminds (Oliver 1996). While theorizing lived experiences of illness has been central to medical humanistic approaches (Barnes and Mercer 1996; Thomas 2007), feminist, disability studies and poststructuralist critiques began in the 1980 s to reveal how medical humanistic accounts remain tethered to the myth of restitution with its acceptance of the normative body and Enlightenment assumptions about human perfectibility, the coherent self and bodily control (Wendell 1996).

To dislodge this universal figure and push against the negative ontologies of difference that it produces, we pick up on and advance emerging theorizing within feminist disability studies and medical posthumanities that engages the fleshy 
materiality and agency of ill, sick and pained bodies (see Patsavas 2014; Price 2017; Rice et al. 2018). While the project of dislodging the universal humanist human is not new (see Braidotti 2003), what is new in our approach is an attention to the artfulness of living with illness, pain and impairment. An attention to artfulness means attending to the sensory, lived, fleshy materiality of illness and pain while holding onto the political dimensions and value of ill and disabled lives. We innovate the concept of "living dis/artfully" to meld the artfulness of living with illness/disability with a non-reductive, non-essentialist approach to the materiality of bodies.

\section{Phenomenology of living dis/artfully}

Feminist philosophers of embodiment and phenomenology have long challenged mind/body and nature/culture dualisms inherited from Descartes and his contemporaries. While varied in their approach, these scholars rethink bodyworld together as one flesh (Merleau-Ponty 1968; Grosz 2005), challenging humanist understandings of the body as a mere extension of mind; a passive, inert substance available for cultural inscription; a container for a universal subject; or a bounded entity that exists outside of human and non-human relationships (Grosz 2005, 118-121). For phenomenologist Maurice Merleau-Ponty (1968) and feminist body philosophers Elizabeth Grosz (2005) and Gail Weiss (1999), consciousness is thoroughly embodied. It is through our bodies that we experience-and create-self, other and world. Body and world, subject and object, inside and outside, meld; they are one flesh. This not only places materiality at the center of theorizing, but also conceives of bodies, of difference, as coming to be in relation. Weiss (1999) calls this "intercorporeality," an ever-unfolding process that emphasizes "continual interactions with other human and 
nonhuman bodies" (5). We use the term intra-relationality to recognize, along with our storytellers, the centrality of relationships (to other humans, technologies, environments, etc.) in the becoming of ill/disabled bodies and lives. This is one way disability studies might re-embody its theories and methods and dislodge the lingering impairment/disability divide along with its Cartesian legacy.

Centering intra-relationality in our theorizing also opens space to artfully explore embodiment for those of us who inhabit bodies in spaces that do not mold to our embodied way of being. Disability studies scholars' Kevin Paterson and Bill Hughes (1999) offer the phenomenological concept of "dys-appearance" to describe this doubleness - the abrupt rub that occurs as we encounter socio-spatial environments that omit our "carnal information," or particular way of experiencing and creating the world. The experience of able-bodies, in contrast, is one of constructing and inhabiting the sociospatial world through putting forth "projects" that utilize and reproduce a narrow band of "hegemonic" carnal information (603). Feminist disability theorist Rosemarie GarlandThomson (2011) captures this double-ness of embodied difference with the concept of the "misfit", which melds new materialism to an arguably phenomenological concept (Weiss 2015, 92) similar to Paterson's and Hughes' dys-appearance. Misfit describes the "jarring juxtaposition" (Garland-Thomson 2011, 593) of flesh and world in which nonnormative bodies do not fit, the "encounter between bodies with particular shapes and capabilities and the particular shape and structure of the world" (594). Focusing specifically on illness and pain (something which Paterson and Hughes touch on but do not make their focus), we develop the concept of "living dis/artfully" to recuperate the fleshy knowledge and surprising bodyworld disjunctures depicted by our storytellers. We 
go beyond the concept of misfit to not only focus on adverse experiences of pain and illness (something Garland-Thompson refers to but does not accomplish in her examples), but also the artfulness—-the creativity, resourcefulness and potential political resistance—of those who do not 'fit'.

\section{Dis/artful becomings}

We graft insights from body becoming theory (see Rice 2014, 2018) to extend our concept of living dis/artfully beyond most embodiment theorizing with its anthropocentric tendencies in centring human consciousness (over nature, the nonhuman and the body). This mixing of approaches offers a complex theorization that accounts for both the embodied and the embedded forces that shape the materialization and lived experience of illness. Rather than being-in-the-world, body becoming theory understands bodies as of the world (Barad 2003, 828), a node within a larger configuration of natural and cultural forces through which bodies become ill, pained, or disabled. This sets ontology into motion within "the temporal forces of endless change," unsettling any taken-for-granted, static or timeless essence to materiality (Grosz 2008, 5). Bodies are historical. They do not exist as bounded entities with agency independent of or prior to relations, but rather become ill through complex, open, fluid, unpredictable, biographical, historical, biological, and cultural entanglements, which they also effect and change (Rice 2014, 21-2; see also Grosz 2008, 5-6). In Karen Barad's (2003) terms, this is the "intra-activity" (or co-constitution) of the material and the discursive where "matter and meaning are mutually articulated" (822). Body becoming theory offers a non-essentialist and non-determinist way to theorize ill embodiment that recognizes context alongside the stubborn recalcitrance of ill bodies and the creative 
renderings of those living with illness in a world that excludes and a body that pushes back (Rice 2014, 22). It also allows us to conceive the storytelling space, through its situated practices, as one wherein we experiment to open more ethical possibilities for becoming ill and disabled otherwise-an argument that has been put forth in this paper and elsewhere (Rice et al. 2018).

Body becoming theory understands matter to have agency—matter is "an active factor in the processes of materialization" (Barad 2003, 827). This means understanding the "materiality of the body as itself an active, sometimes recalcitrant force that [...] punches back at humans" (Alaimo and Hekman 2008, 4, 7). Bodies become debilitated by pain and shaky from progressive disease. They defy the myth of human control and unsettle the normative notion of embodiment haunting illness (and wellness) narratives. The concept of living dis/artfully keeps illness moving as an emergent process that incorporates the discursive, the lived, and the material. It renders storytellers' experiences artfully and offers a non-reductive, non-essentialist reading of the agency of ill bodies intra-relationally with other human bodies, technologies, culture and power. We turn now to the stories.

\section{Re-storying IIIness Experiences as Dis/Artful Becomings}

We selected seven multimedia stories from our storytelling project archive (of over 600 videos) that evidence the dis/artful experiences of ill people in a world that is structured by and reproduces a particular mode of embodiment derived from Enlightenment constructs of the normative human and hierarchies of the able bodymind. We explore the ways in which illness emerges in these stories as materially, politically 
and relationally consequential-a sensory-material intra-relationality formative of body, self, world. Each of the stories we describe recovers and reclaims the fleshy knowledge of ill people themselves as a way to live artfully with and speak back to illness and marginalizing social experiences. We offer descriptions that 'get close' to the experiences artfully rendered by our artist-storytellers; and in our analysis emphasize the fleshy disruptions that open possibilities for living well with illness. The knowledge that storytellers (and their bodies) hold about illness is generative and disruptive, inviting outsider attendance to illness in both embodied and embedded ways.

\section{Relationality and Rupture}

Our first two stories explore the theme of relationality and rupture in ways that move beyond illness as a tragedy that must be overcome through individual will and biomedical heroism. Storytellers depict disjuncture—bodily and socially—as well as artfully living with/in bodyminds that do not fit: family relationships, memory, foremothers, pain, distress, disability community, pills and technology commingle in the videos as storytellers reclaim intimate fleshy knowledge of illness, re-story their lives as worth living and speak back against exclusionary systems and the standard of the humanist human.

In Untitled, disability-identified artist storyteller Tanya Workman foregrounds how stigmatizing and pathologizing frames of illness submerge embodied knowledge about illness within her family (https://revisioncentre.ca/living-dis-artfully; password "artfully"). Workman begins by remembering her grandmother who took pills, was hospitalized and received electroshock treatment for psychiatric illness. As though in a conversation, she employs "you" to speak directly with her grandmother, and accompanies this direct 
address with dimly lit interior scenes, inviting us to consider how illness might unfold and enfold in intimate spaces and personal exchanges. The story registers family silence around Workman's grandmother's illness, filled as it is with questions about her grandmother's experience that may be helpful for Workman to have answers to now. "It's been ten years since I've filled my first prescription, for Zoloft," she discloses, her own engagement in psychiatric services perhaps prompting wonderings about her grandmother's experience. "What was the first sign? Anxiety? Mood swings? Did it come before you had children? Or after? Or maybe there wasn't a sign." Workman's wonderings register the loss of embodied knowledges about psychiatric illness when the only frame available to address mental distress is that of pathology. She shares, "I often wonder how your life would have been different if now was then, if then was now." One can hear in this query an echo of the narrative of advances in psychiatric medicine, but perhaps also a collapsing of time, a bridging of distance between "then" and "now" that the immediate intimacy of her direct address also accomplishes. What would Workman's grandmother offer her, knowing that Workman too takes medication to manage psychiatric illness? And what does she offer her grandmother in speaking what is difficult to speak? Whatever insight her grandmother may have had to offer, Workman is subsumed under the authority of "the hospital" and prescribed treatments. Workman's grandmother's sparse words, "They zapped me good," mark also what was unspeakable between her and Workman.

Workman's story, her and her grandmother's intertwined illness narratives, do the delicate and intimate work of building connection around what is absent and abject. Her story teaches how tracing illness through family relationships has the potential of 
offering new histories and points of intra-relation between past and present, grandmother and granddaughter, body and mind, medicine and disability studies.

Outside of the confines of pathologizing psychiatric discourse, Workman's grandmother's illness, retrieved from abjection and re-incorporated back into embodied memory and family history, takes on new meaning, becoming potentially transformative for her granddaughter. This story reclaims shared body knowledges often stolen through stigma, isolation, objectifying biomedical frames, encounters from our family stories—even disability studies approaches that evacuate knowledges of mindbody pain. Workman's many unanswered questions about her grandmother's and her own mental difference/distress leave open these experiences to multiple intra-acting forces that may be implicated in their materialization. Though Workman confesses a lack of "insider knowledge," she uses the shared experience of psychiatric illness with her grandmother as a way to create connection and new meanings around stories of stigmatized illness experiences, and in so doing to begin to rewrite and reincorporate memories and fleshy knowledge that had been lost to her.

In their story, puzzle piece, gender queer artist mel g. campbell, too, reimagines illness as a complex and contradictory site of relationality and rupture (https://revisioncentre.ca/living-dis-artfully; password "artfully"). Their account begins with the invocation of Black feminist foremothers June Jordan, Octavia Butler, Audre Lorde, and campbell's own mother, and is populated by other disabled people such as $L, A$, and $R$, who each encounter a confluence of raced, classed and disability-related exclusions in Toronto. campbell's narration is paired with still images and short video clips of housing complexes, empty streets, flowers and roadside debris that together 
depict a formerly impoverished, now gentrifying neighbourhood in the city. We see these public spaces through campell's eyes, having been invited to wonder what it might take to make one's way through this architectural and political borderland as a woman using a wheelchair, a poor Deaf woman, a Black man with a limp, and finally as campbell, a Black genderqueer chronic pain sufferer who walks with a cane. Other voices that populate the video include that of campbell's father, a first-generation immigrant with his own reasons for denying their chronic pain, a doctor "friend" who "hates chronic pain patients," and phantoms of doctors campbell themselves have seen who concur.

Unlike these others who call on professional power to create easy explanations for their chronic pain, campbell's story does not reach for neat resolution: it is clear to campbell that "this pain is for life." Still, the artful invocation of a consciously created community, a chosen lineage and relationships with political foremothers and her own mother offer a different way of becoming ill/disabled, of bearing the weight of other's marginalizing and objectifying illness stories. campbell's understanding of pain as at once physical and social documents an unfolding and enfolding of illness as it intersects with race, class, sexuality and gender in the streets, and through relationships with others who share experiences of intersecting oppressions. Illness becomes a site of transformative community relationships: campbell's story pulls together and shores up alternative voices, past and present, building for themselves and their viewers a nascent disability culture created by people like them. Through this, campbell can tolerate "a lifetime of worn wounds" and summon strength to carry on in the face of their bodily pain as it entangles with social suffering. In and through its artful rendering of 
relationality and rupture, campell's story inserts new and dis/artful ways to understand and live with illness that push back against the misfitting of ill, racialized queer bodies from accounts that bound the human as autonomous and evacuate knowledge of living with/in illness and pain.

\section{The Stubbornness of III Bodies: On Pain and Suffering}

For that is one property of poetic language: to engage with states that themselves would deprive us of language and reduce us to passive sufferers.

Adrienne Rich, What is Found There, 10

We turn in this section to consider what our artist-storytellers have to tell us about living with pain, distress and suffering, whether as the disruption of the myth of the humanist human and coherent self or the alienation that results from undertreated and inescapable physical pain. There is something stubborn and uncompromising-both intractable and tenacious_-about ill bodies that pushes back in this next set of videos, a challenge to disability studies to incorporate bodies in pain and medical humanities to unsettle lingering ties to coherent illness narratives and restitution. We analyze three stories and the new scripts their ill tellers create to artfully live with pain and bodily suffering. The fleshy flows and insistent sensations in this section bring us close up to lived experiences of pain in ways that move beyond the unspeakable, as Adrienne Rich writes in our opening quote, to living dis/artfully and making new meaning of pain.

In her film, In the Autumn of 2010, nursing professor and former nurse, Gail Lindsay narrates how she comes to make sense of the sudden onset of chronic radiating leg and back pain, and the subsequent daily endurance of ineffective medical tests, treatments and therapies (https://revisioncentre.ca/living-dis-artfully; password 
"artfully"). As the image of Andrew Benyei's "Sun Goddess" sculpture fades from the screen, Lindsay turns to women's literature to begin to make sense of her experience anew. She recites Emily Dickenson's poem (1924/1960, 323-324) "XIX” on pain:

Pain has an element of blank;

It cannot recollect

When it began, or if there were

A day when it was not.

It has no future but itself, Its infinite realms contain Its past, enlightened to perceive New periods of pain The poem's focus on pain as endless and unbounded, and as part of life, dovetails with Lindsay's narration of a life now stripped down by pain to survival, starkness and uncertainty: "For the first time I understood how this kind of suffering makes people want to die." To become unstuck from being "exquisitely stopped in place," Lindsay turns to "what this culmination of life-long processes has to say," asking, "What does my body know that I need to wake up to?" These questions suggest that recuperating fleshy knowledge is a way for Lindsay to birth a new and richer life-story with pain, issuing an invitation to attend to pain differently by centering lived experience and her own bodily knowledge. Biomedical narratives do not offer the possibility of this more complex narrative, constructing as they do a grim prognosis of deteriorating lumbar disks, reduced quality of life and ineffective medical intervention. Similarly, Lindsay's invitation challenges disability studies to embrace the realities and stubbornness of pain and impairment within its approaches and theories, and medical humanities to rethink familiar or pre-set narratives (such as restitution, quest or chaos) 
(Frank 2013) that arguably continue to value coherence and the ideal of the normative humanist human.

In her untitled story, researcher and artist Nadine Cross brings viewers close up against the complexity and uncompromising quality of depression

(https://revisioncentre.ca/living-dis-artfully; password "artfully"). Her static illustration and measured narration describes: "My sadness looks like... [blank screen]. My sadness feels like...someone is standing on my chest. It's hard to breath. And my heart aches." Cross does not offer a story to explain her sadness. It is enough to say, "Depression is a pattern of my life, for life." Indeed, it appears that for Cross not having a story about depression-except that it just is and will be- offers some relief, possibly the escape from unrelenting pressure to search for a cure that such recognition might afford. As in Workman's narrative, Cross' refusal of an origin story does not signify her failure (to know, to master depression, to find the cure) but rather her refusal to close down meanings of depression, and her vulnerable willingness to leave open the story of causes and responses to those that best resonate with her embodied experience. Acknowledging the facticity of depression is a "...compassionate gift of selfunderstanding" that shifts the inquiry from "Why?" to "What helps?" Cross' story offers a novel response to illness, not as something that must be (or can be) "fixed," (or fully explained and accounted for) but as something that can be lived in, through and alongside of, with enough of, "what helps." In her exploration of the boundaries between living with and not living at all, Cross gives witnesses the gift of vulnerability with which we might connect. Cross unravels the myth of the universal human as one who is free from illness, suggesting the need for more complex understandings that can address 
both lived experience and structural exclusions or stigma around illness. This revalues the bodily knowledge of ill people themselves.

In our final story in this section, artist-storyteller Carolyn Pletsch weaves a narrative of uncompromising, degenerative neurological illness against the backdrop of photographs of a "crumbling" Havana snapped while in Cuba with her family (drawing a metaphorical association between body and city that perhaps alludes not only to the coexistence of beauty and physical decay, but also to the importance of telling our stories within shifting landscapes with complex histories) (https://revisioncentre.ca/living-disartfully; password "artfully"). First noticed as a "tremor" that "began as a small thing: intermittent, non-threatening, benign," Pletsch describes the strange irony of living with a debilitating "progressive" illness. Her use of biomedical language moves the viewer close to the sheer force of illness and ideal of the normative human: "Idiopathic." "Disorder." "Tremour.” "Rigidity." "Frozen." "Mask." "Fatigue.” "Weakness." For Pletsch, however, the ineffability of illness — that enfolding of body with a life lived in relation to others and world—cannot be captured by familiar humanist and biomedical language alone. Pletsch struggles against these framings to make meaning and claim her voice even as she mourns her lost self, plans and "space and place." It is within the cross winds of conflicting flows in her life between normative expectations from family-that she participates in life-as well as offers of help from friends commingled with their "confusion" and "indecision," that Pletsch finds new meaning and purpose. Her new place with and in illness is uneasy-it not only contains grief, discomfort, bodily disorder, but also love, blessing and purpose. In her artful assembling of the contradictory aspects of illness, Pletsch, along with the other artist-storytellers in this 
section, opens new possibilities to live artfully with illness. Illness and pain are part of life and being and becoming as human.

\section{Speaking from the Body: Re-storying Bodily Scripts}

In our final set of films, we encounter ill bodies as a site where conflicting and contradictory discourses coalesce. This third set engages with the struggles and challenges that storytellers confront in reconciling conflicting discourses surrounding illness and received bodily scripts. Between the push and pull of medical intervention and pharmacological treatments that frame bodily selves as pathological, and engagement in art that re-stories illness and pain, the storytellers in this section forge new storylines. These are rooted in embodied timelines resistant to biomedical and humanist logics and practices marginalizing of their bodyminds.

This Person(ality) is not Pathological, created by disability studies student Amber Reid documents conflicting discourses surrounding her body and way of being, along with her struggle reconciling these (https://revisioncentre.ca/living-dis-artfully; password "artfully"). Born three months premature and "with an abnormally large head," constructions of Reid's difference started early. Doctors proposed a shunt to drain excess fluid, yet her grandmother offered an alternative reading. Reid's large head was a "Reid head" appropriately belonging to Reid, and creating affiliation between her difference and that of others in the family. Reid's "desire for structure, sameness, and security" was similarly respected, understood by the family as a "preemie personality" rather than a psychiatric disorder. Later in her life, Reid encounters pathologizing discourses, her difference now coded as generalized anxiety or borderline personality disorder. For Reid, an acknowledgement of the facticity of "what is"-her large head and 
desire for sameness—comes up against a psychiatric discourse that makes its own claims to objectivity. Reid says, "There is a tug of war over my flesh. I no longer know where my loyalty lies." Reid's struggle raises important questions: What ways do we have of understanding and living with embodied difference? How do normalizing and pathologizing discourses co-exist in the lives of ill people, who are often engaged in medical intervention and pharmacological treatment at the same time as they resist such discourses and create alternative possible worlds marked by alternative meaningmaking around illness-experience?

Snyder and Mitchell (2001) note that a contribution of disability studies is the understanding that received scripts on disability represent "deep-seated, yet uninterrogated, cultural conflict" (377). This cultural understanding of disability reveals how institutional and cultural investments in the normative human work to demarcate, control, and contain the disruptive potential of bodily difference as a challenge to a normative social order built on the idealized able-bodymind. The simultaneous cultural investment in the construction of, and desire to get rid of disability identified by Synder and Mitchell plays out in Reid's story. The "war" being "fought over [Reid's] flesh" shapes her ambivalent engagement with her own body, permeates social and familial relationships, and unjustly places shame on her. For many whose bodily selves manifest difference, the elusive promise of the able body, supposedly achievable through medical treatments and interventions, often does more harm than it does provide reassurance for recovery. In her struggle over received scripts of her different body and the multiplying of possible readings, Reid opens possibilities for living with difference as fundamental to being/becoming as human. 
The video work of disability artist Elaine Stewart, slide/cascade, also grapples with and speaks back to received and contradictory discourses surrounding illness and disability (Rice et al. 2017) (https://revisioncentre.ca/living-dis-artfully; password "artfully"). Stewart's opening scene unfolds in fragments, "Things to do before transferring patient / Remove IV line. / Do not warn patient of length and depth of line. / Nurses stand around the bed and they talk to each other. / They keep pulling the line out, they keep talking, / nobody really acknowledging me on the bed." The jarring incoherence of these lines, and Stewart's use of the present and present continuous tense juxtaposed with an experiencing "me" echoes Frank's (2013) framing of the chaos story of illness. The chaos story is characterized by the experience of passivity and the absence of "narrative order" or coherence (Frank 2013, 97). Through the chaos story we are invited by Stewart into a scene that is both horrifying and absurd. And yet, the mock-instructional tone Stewart uses reveals the workings of biomedical understandings of illness/disability in this encounter as that which calls forth the chaos narrative. The nurses' instrumental actions come from somewhere, are taught and practiced, driving home the frequency with which ill bodies are instrumentalized, dehumanized and exposed to routines of "violence and violation" (Weingarten 2013, 91). The normative human underlying such practices is further revealed by Stewart through a written dictionary definition of the word "disability" that flashes on the screen- "disadvantage, RESTRICTION, / affliction, ailment, defect, detriment / disqualification, drawback, impairment, / inability, incapacity, incompetency / inexperience, infirmity, injury." Stewart's artful rendering of a medical encounter restories the "chaos narrative" as a way of documenting —and paradoxically making 
coherent-the effects of biomedicalized social and material processes that come to bear on ill bodies, suggesting that ill bodies themselves are not the problem.

In contrast to the fragmentary speech of this initial chaos story, Stewart's citation of her encounter with a psychiatrist's account of the postpartum hormonal cascade retains fluency and coherence. Against a backdrop of cascading and unravelling wheelchairs, Stewart recounts that the hormonal cascade "... makes breastmilk flow for the child. / At that point / the body is producing a high level of prolactins / the psychiatrist said that the level of prolactins $/ \ldots / \ldots$ in a post-pregnant breastfeeding woman / is at the same level as a patient suffering from a psychosis." Undoubtedly, the proximity of things that are not thought to go together-ecstasy/strife (Rice et al. 2017), care/harm, and now, reproduction/madness—calls into question received cultural ideas and ideals about bodily control and what the body can experience. The final scene of Stewart's video is a long shot of a "STOP" sign spinning in the current as water drains out around it. The ceaseless spinning of an object that says "STOP" is reflective of other visual vocabulary employed in the video. "Your body. Get over it," announces the impossible injunction to leave a thing which cannot be left, to the unraveling, cascading wheelchairs, which contrast themselves with wheelchairs as we would expect to see them, sturdy, metallic and stable. Stewart's story rewrites scripts of illness and disability as an unexpected, contradictory, painful and sensuously embodied tale; it can be difficult to watch, perhaps also difficult to live.

Reid and Stewart's stories artfully re-write received bodily scripts of illness, but in so doing, they do not offer any comfortable resolution to the contradictions or difficult carnal knowledges they impart. Instead, they enact a different version of illness as 
fundamental that might prove helpful in breaking open a culture invested in conceptualizing illness and disability in ways that are deeply overdetermined. These artist-storyteller depictions of living with illness suggest new ways to orient to illness within both disability studies and medical humanities: the stories embrace previously marginalized carnal knowledges to banish the humanist human from medical humanities approaches and re-embody disability studies.

\section{Conclusion: Recuperating the Carnality of Illness through Art}

In this paper, we have explored how the multi-media stories of illness experiences presented here invite audiences to re-embody theory through body becoming and phenomenological frames and to re-imagine illness outside the normative human standard of healthy, pain-free bodyminds. In these stories, illness is fundamentally intra-relational: illness emerges in the co-constitution and confrontation of bodyminds with worlds; illness is not determined by language or culture alone but rather the storytellers' experiences are also shaped by the body's visceral and sensory existence and insistence; and finally, illness disrupts narratives of mastery (including accounts privileging coherence, restitution, closure and even chaos) and instead insists on the agency of the corporeal and the de-centering of human consciousness, will and ordering. For example, Workman's video leaves many unanswered questions about her grandmother's and her own mental difference/distress and intentionally leaves open these experiences to multiple intra-acting forces that may be implicated in their materialization (and perhaps implicitly advocates her desire for a similar openendedness in others' responses to such distress). In campbell's rendering, illness 
unfolds and enfolds as an at once physical and social experience that intersects with race, class, sexuality and gender and becomes a site of transformative community relationships. Cross' refusal of an origin story allows her (and us) to leave open the story of causes of and responses to depression to those that best resonate for her, thus revaluing her bodily knowledge and suggesting a need for more complex intra-relational understandings. Finally, in bringing together contradictions-bodily chaos and order, sensuous experience and instrumental medical routines-Stewart disrupts received scripts about bodily control and order as a universal feature of the normative human, revealing instead the artifice of such imposed standards and the complexity of ill embodiment.

In featuring and analyzing these stories, we have demonstrated how in disability arts community, people living with illness might recover and reclaim invaluable "carnal information" as central to ethically and politically responsive illness theorizing. We have been guided in our analysis by theorists who share our desire to re-centre the energies and materialities of bodies within disability studies and to advance new narratives of difference beyond humanist ones within the medical posthumanities. Melding phenomenology and body becoming approaches together has allowed this complex exploration of illness and pain, holding together, for example, the stubborn insistence of ill bodies, the crushing bodily effects of oppression, the instrumentality of technology in everyday lives and the meaning made of illness experience. This melding of approaches moves current theorizing about illness and disability beyond evacuating bodies from theory or subtly leaving in place negative ontologies of illness and opens space to imagine new possibilities for living dis/artfully with illness as fundamental. 
Indeed, the multimedia stories presented here evidence sophisticated socio-political analyses and critiques of contemporary ways of understanding and (de)valuing illness. By asserting that illness narratives have something of value to offer ill people, illness scholarship and understandings of embodiment more broadly, we hope these narratives and the human diversity they story come to be valued as instructive, generative, and fundamental parts of public culture.

Informed consent was obtained from all individual participants included in this study. Additional informed consent was obtained from all individual participants for whom identifying information is included in this article. All procedures performed involving human participants were in accordance with the ethical standards of the institutional and/or national research committee and with the 1964 Helsinki declaration and its later amendments or comparable ethical standards.

\section{Acknowledgements}

This research was supported by the Gender and Health Institute of the Canadian Institutes of Health Research (CIHR), the Canada Research Chairs (CRC) Program, and the Canadian Foundation for Innovation (CFI).

We acknowledge the Re•Vision Centre for Art and Social Justice at the University of Guelph for incubating our intersectional and intersectorial research creation methods, the School of Disability Studies at Ryerson University for the generous donation of accessible workshop space, and Tangled Art + Disability, whose funding assisted us in pushing the creative boundaries of our work. We also want to thank workshop facilitators Eliza Chandler, jes sachse, Manuela Ferrari, Lindsay Fisher, Fran Odette, 
Lorna Renooy, Tanya Workman, Janna Brown, Liz Brockest, Hannah Fowlie, Ingrid Mundel, and Rani Sanderson, and the artists and storytellers who participated in our many workshops held throughout the province of Ontario. We especially wish to thank Dawn Matheson and Kimber Sider, who captioned the films and who coached us in the art of audio recording and Wanda Fitzgerald, who undertook the audio description.

\section{References}

Alaimo, Stacy and Susan Hekman. 2008. "Introduction: Emerging Models of Materiality in Feminist Theory". In Material Feminisms, edited by Stacy Alaimo and Susan Hekman, 1-19. Bloomington: Indiana University Press.

Barad, Karen. 2003. "Posthumanist Performativity: Toward an Understanding of How Matter comes to Matter." Signs: Journal of Women in Culture and Society 28, no. 3: 801-31.

Barnes, Colin and Geof Mercer, eds. 1998. Exploring the Divide: Illness and Disability. Leeds: The Disability Press.

Braidotti, Rosi. 2013. The Posthuman. Cambridge: Polity Press.

Chandler, Eliza, Nadine Changfoot, Carla Rice, Andrea LaMarre, and Roxanne Mykitiuk. 2018. "Cultivating Disability Arts in Ontario." Review of Education, Pedagogy, and Cultural Studies, 40 no. 3: 249-264.

Clare, Eli. 2017. Brilliant Imperfection. Durham: Duke Press.

Couser, G. Thomas. 1997. Recovering Bodies: Illness, Disability and Life Writing. Madison: University of Wisconsin Press.

Dickenson, Emily. 1960. The Complete Poems of Emily Dickenson, edited by Thomas H. Johnson. Boston: Little Brown. (Original work published 1924)

Douglas, Patty, Carla Rice, Kathryn Runswick-Cole, Anthony Easton, Meg Gibson, Julia Gruson-Wood, Estee Klar and Raya Shields. 2019. "Restorying Autism: A Body 
Becoming Disability Studies in Education Approach." Journal of Inclusive Education. https://doi.org/10.1080/13603116.2018.1563835

Douglas, Patty. 2013. "As if You Have a Choice: Autism Mothers and the Remaking of the Human." Health, Culture \& Society 5, no. 1: 167-181. DOI 10.5195/hcs.2013.137

Erevelles, Nirmala. 2011. Disability and Difference in Global Contexts: Enabling a Transformative Body Politic. New York: Palgrave Macmillan.

Frank, Arthur W. 2013. The Wounded Storyteller: Body, IIIness and Ethics (2 ${ }^{\text {nd }}$ edition). Chicago: University of Chicago Press.

Fritsch, Kelly. 2016. "Cripping Neoliberal Futurity: Marking the Elsewhere and Elsewhen of Desiring Otherwise." Feral Feminisms 5 (Spring): 11-26.

Garland-Thomson, Rosemarie. 2011. "Misfits: A Feminist, Materialist Disability Concept." Hypatia 26, no. 3 (Summer): 591-609.

Grosz, Elizabeth. 2005. Time Travels: Feminism, Nature, Power. Durham: Duke.

Kumari Campbell, Fiona. 2005. "Legislating Disability: Negative Ontologies and the Government of Legal Identities." In Foucault and the Government of Disability, edited by Shelley Tremain, 108-130. Ann Arbor: The University of Michigan Press.

Lee-Shanok, Philip. 2016. "New SickKids Campaign Puts 'Fierce' New Face on What it Means to be Sick." CBC News, October 15, 2016. http://www.cbc.ca/news/canada/toronto/new-sickkids-campaign-puts-fierce-newface-on-what-it-means-to-be-sick-1.3806051.

Merleau-Ponty, Maurice. 1968. The Visible and the Invisible. Evanston: Northwestern University Press.

Montgomery, Phyllis, Sharolyn Mossey, Carla Rice, Karen McCauley, Eliza Chandler, Nadine Changfoot and Angela Underhill. 2019. "Health Care Providers as Creators of Digital Stories about Disability and Difference: 'Now What?'” 
Canadian Journal of Nursing Research, 7th March, 2019, online advance publication. https://doi.org/10.1177/0844562119835130

Oliver, Michael. 1996. Understanding Disability: From Theory to Practice. New York: St. Martin's Press.

Orsini, Michael and Anne McGuire. 2016. "Sickkids' New Ad Campaign: Fighting Words?" Impact Ethics, October 19, 2016. https://impactethics.ca/2016/10/19/sickkids-new-ad-campaign-fighting-words/.

Paterson, Kevin and Bill Hughes. 1999. "Disability Studies and Phenomenology: The Carnal Politics of Everyday Life." Disability \& Society 14, no. 5: 597-610. https://doi.org/10.1080/09687599925966

Patsavas, Aly. 2014. "Recovering a Cripistemology of Pain: Leaky Bodies, Connective Tissue, and Feeling Discourse." Journal of Literary \& Cultural Disability Studies 8, no. 2: 203-18. https://muse.jhu.edu/article/548851

Picard, A. 2016. "SickKids Campaign Forgets that Children aren't Always Warriors." The Globe and Mail. October 25, 2016. https://www.theglobeandmail.com/opinion/sickkids-campaign-forgets-thatchildren-are-not-always-warriors/article32498752/.

Price, Margaret. 2017. "What is a Service Animal? A Careful Rethinking." Review of Disability Studies 13, no. 4: 53-66.

Rice, Carla. 2014. Becoming Women: The Embodied Self in Image Culture. Toronto: University of Toronto Press.

Rice, Carla. 2018. "The Spectacle of the Child Woman: Troubling Girls in/and the Science of Early Puberty." Feminist Studies, 44 no. 3: 535-566.

Rice, Carla, Eliza Chandler, Elizabeth Harrison, Kirsty Liddiard and Manuela Farrari. 2015. "Project Re・vision: Disability at the Edges of Representation." Disability \& Society 30, no. 4: 513-27. https://doi.org/10.1080/09687599.2015.1037950 
Rice, Carla, Eliza Chandler, Kirsty Liddiard, Jen Rinaldi and Elizabeth Harrison. 2018. "The Pedagogical Possibilities for Unruly Bodies." Gender \& Education 30, no. 5: 663-682. DOI: 10.1080/09540253.2016.1247947.

Rice, Carla, Eliza Chandler, Jen Rinaldi, Kirsty Liddiard, Nadine Changfoot, Roxanne Mykitiuk and Ingrid Mündel. 2017. "Imagining Disability Futurities." Hypatia: $A$ Journal of Feminist Philosophy 32, no. 2: 213-229.

\section{https://doi.org/10.1111/hypa.12321}

Rice, Carla, Andrea LaMarre, Nadine Changfoot and Patty Douglas. 2018. "Making Spaces: Multimedia Storytelling as Reflexive, Creative Praxis." Qualitative Research in Psychology, $27^{\text {th }}$ March 2018, online advance publication. DOI: $\underline{10.1080 / 14780887.2018 .1442694}$

Rice, Carla, Andrea LaMarre and Roxanne Mykitiuk. 2018. "Cripping the Ethics of Disability Arts Research." In Handbook of Ethics in Critical Research: Stories from the Field, edited by Catriona Macleod, Jacqueline Marx, Phindezwa Mnyaka and Gareth Treharne, 257-272. London: Palgrave.

Rice, Carla and Ingrid Mündel. 2018. "Story-making as Methdology: Disrupting Dominant Stories through Multimedia Storytelling." Canadian Review of Sociology, 55(2): 211-231.

Rice, Carla and Ingrid Mündel. 2019. "Multimedia Storytelling Methodology: Notes on Access and Inclusion in Neoliberal Times." Canadian Journal of Disability Studies, 8, no. 2: 118-146.

Rich, Adrienne. 2003. What is Found There: Notebooks on Poetry and Politics. New York: W. W. Norton \& Company.

Snyder, Sharon. L and David T. Mitchell. 2001. "Re-engaging the Body: Disability Studies and the Resistance to Embodiment." Public Culture 13, no. 3: 367-89.

Sontag, Susan. 1978. Illness as Metaphor. New York: Farrar Straus \& Giroux

Thomas, Carol. 2007. Sociologies of Disability and IIIness: Contested Ideas in Disability Studies and Medical Sociology. Basingstoke, England: Palgrave Macmillan. 
Viscardis, Kate, Carla Rice, Victoria Pileggi, Angela Underhill, Nadine Changfoot and Eliza Chandler. 2018. Difference within and without. Qualitative Health Research, $18^{\text {th }}$ November, 2018, online advance publication. DOI: 1049732318808252.

Weingarten, Karen. 2012. "Sorrow: A Therapist's Reflection on the Inevitable and the Unknowable." Family Process 51, no. 4: 440-455. DOI 10.1111/j.15455300.2012.01412.x

Weiss, Gail. 1999. Body Images: Embodiment as Intercorporeality. New York: Routledge.

Weiss, Gail. 2015. "The Normal, the Natural and the Normative: A Merleau-Pontian Legacy to Feminist Theory, Critical Race Theory and Disability Studies." Continental Philosophy Review 48, no. 1: 77-93. https://doi.org/10.1007/s11007014-9316-y

Wendell, Susan. 1996. The Rejected Body: Feminist Philosophical Reflections on Disability. New York: Routledge. 